\title{
Exploring the Differences Between Educational Consultant's and Teachers' Perceptions on Teachers' Needs of Professional Development
}

\author{
Nada Wehbe ${ }^{1}$ \\ ${ }^{1}$ Department of Integrated Studies in Education, McGill University, Montreal, Canada \\ Correspondence: Nada Wehbe, Department of Integrated Studies in Education, McGill University, Montreal, \\ Canada. E-mail: nada.wehbe@mail.mcgill.ca
}

Received: March 5, 2019

Accepted: May 2, 2019 Online Published: July 4, 2019

doi:10.5539/jel.v8n4p64

URL: https://doi.org/10.5539/jel.v8n4p64

\begin{abstract}
The study aims to investigate whether there is a discrepancy between educational consultants and teachers' perceptions on teachers' needs of professional development. The study also intends to answer the following research question: Is there a discrepancy between the perceptions of educational consultants and teachers of teachers' needs in professional development? Moreover, two sub research questions were addressed: How do teachers perceive their needs for PD? How do educational consultants prepare for PD sessions/programs? The participants of the study are twenty pre/lower elementary school teachers and one educational consultant in Beirut. The methodology used to conduct the study was mixed-methods: a qualitative analysis was conducted for the consultant's interview questions and a quantitative analysis for the teachers' questionnaire. Results showed slight differences between the perceptions of teachers on PD and that of the consultant.
\end{abstract}

Keywords: educational consultancy, professional development, workshops, schools, teachers' professional development

\section{Introduction}

\subsection{Background of the Study}

\subsubsection{Who Provides Professional Development (PD)?}

Many may be unaware of the importance of professional development providers in offering teachers' quality training. These providers vary from private educational institutions, educational consultancy (EC) firms to governmental institutions. According to Bailey (2006) "educational consultancy is a technical process which aims to improve teaching and learning through the care, guidance and simulation of continued development for not only teachers but also any other person having impact on the educational context" (as cited in Hismanoglu \& Hismanoglu, 2010, p. 18). In other words, educational consultancy provides professional consultation in the designing of curriculum guidelines and education programs as well as conducting professional training for teachers, principals, coordinators, and any educational organization. This involves "extensive communication with the stakeholders to facilitate interpretation and implementation of the new education programs and projects to conduct professional development training, and to evaluate the effectiveness of the program" (Grey Matters Education, 2015). According to Hismanoglu (2010, p. 20), some duties or services of educational consultancy firms may involve: "supporting the leadership team for the professional development of teachers demanded by new programs, and offering surveys to monitor response to programs and conduct assessments of program effectiveness".

\subsubsection{Teachers' Needs for Professional Development (PD)}

A major component of educational consultancy is professional development (PD). "Twenty-first-century educational reform in the West and in Lebanon has stressed the importance of improving schools to meet and address changes in how students learn regarding active learning, technology or other aspects of the teaching/learning process through in-service PD programs" according to Nabhani, Nicolas, and Bahous (2013, p. 2). According to Paik et al. (2011), since teachers are the most important implementers of reform, PD is a major factor to accomplish the objectives of reform. Educational professional development of teachers has become the 
center focus of school improvement. In addition to that, many research studies (Garet et al., 2001; Panuel, 2007) have shown how professional development can influence teachers' knowledge and practice. Moreover, during their careers, teachers face many challenges when updating their knowledge and skills, due to the introduction of new curricula, changes in technology, and changes in learning needs of students. Therefore, Kolnik (2010) found that teachers are in need of appropriate in-service training as a foundation for further training, and to prevent ineffectiveness of PD programs.

\subsubsection{The Characteristics of Effective Professional Development Programs}

The characteristics of effective professional development programs were proposed by Guskey (1995). First of all, "any PD implemented must be without major disruptions or extra work requirements for the teacher, and changes would be initiated slowly. Second, teachers must be given evidence that the changes being implemented are effective. The third principle pointed to the need for continuing support and follow-up" (As cited in Mattenson, Ozel, \& Zientek, 2013, p. 570). Moreover, Mizell (2010) stated that effective professional development empowers teachers to develop the knowledge and skills they need to improve students' learning. To be effective, professional development must entail considerable planning followed by careful implementation with feedback to ensure it responds to educators' learning needs.

Desimone (2009) identified critical PD characteristics as "(a) content focus, (b) active learning, (c) coherence, (d) duration, and (e) collective participation" (as cited in Mattenson, Ozel, \& Zientek, 2013, p. 570). The duration characteristic of the professional development experience was also suggested in many studies. In relation to this, Hammond and Richardson reported that "Professional development lasting 14 or fewer hours showed no effects on learning. The largest effects were for programs offering 30-100 hours spread over 6-12 months" (as cited in Mattenson, Ozel, \& Zientek, 2013, p. 570). Regarding the other aspects, studies consider that quality PD needs to focus on specific topics that engage teachers in active learning and teams' participation.

Therefore, based on the researcher's previous experience in teaching, terms such as PD, educational consultancy, curriculum development and design, were not so common in the school where she worked. However, such terms were introduced during her graduate courses and in my research and readings, and became clearer in meaning with time. Some teachers are willing to improve themselves either by taking courses or by attending local and international conferences according to their needs and time. Unfortunately, many PD programs concentrate either on the content or on the teaching methods (Steyn, 2007) but recently some PD agencies that are for profit claim that they are preparing and offering PD sessions that are relevant to teachers' work and needs. According to Steyn $(2007$, p. 157) "...the professional development of teachers has changed during the past two decades from a "one size fits all" model to more continuing, content—and pedagogically—focused programs..."

\subsection{The Studys}

Many studies have been conducted to show the importance of professional development in improving teaching practice and learners' performance. In 2007, Steyn noted that "publications on PD in the last decade have shed light on effective PD programs that develop teachers' knowledge and skills; improve teaching practice and raise learners' performance" (p. 160). However, not much research has been conducted on educational consultancy agencies and teachers' perceptions of their own PD needs (Alshamrani et al., 2014). Additionally, it is not clear how educational consultants prepare or organize their PD programs; however, according to Fayez, Alshamrani, and Mansour (2014) providers of knowledge and skills are the key in the success of any professional development experience, which means that EC or PD providers are essential in the success of any PD program. In their study, Alshamrani et al. (2014), found that when providers were asked about how they plan for teachers' professional development, they directly responded that training is usually coordinated by the Ministry of Education and clearly showed that they do not have any influence in the participation and preparation of the PD programs.

This applies too to the Lebanese research market where not much research has been done on the educational consultants and teachers' perceptions of their PD needs. According to Nabhani, Nicolas and Bahous (2013), several studies in Lebanon found that PD programs have not been tailored to meet the increasing number of challenges. For example, teachers still "lag behind in their knowledge and skills in technology as a tool to communicate with and promote students' academic knowledge; a tool that has become principal in how young people learn" (p. 2).

Therefore, many schools and principals provide their teachers with professional development sessions, however, neither schools nor agencies/consultancies/PD providers follow up and monitor teachers' implementation or needs' assessments. Therefore, based on this and on the researcher's experiences, this research study was conducted to address this issue. 


\subsection{Purpose of the Study}

This study shed light on one of the educational consultancies that are the rising external educational agencies in Lebanon, which offer professional development programs. As well, it checked whether there are differences between their perspectives and those of teachers regarding teachers' professional development needs and training. Therefore, the purpose of this study was to investigate whether there are discrepancies between the perceptions of one PD provider (educational consultancy) and those of teachers in one school in Beirut concerning teachers' needs for PD. Specifically, this study aimed to answer the following research question: Is there a discrepancy between the perceptions of educational consultants and teachers of teachers' needs in professional development?

Two sub questions were addressed in the process:

1) How do teachers perceive their needs for PD?

2) How do educational consultants prepare for PD sessions/programs?

\subsection{Significance of the Study}

Findings of this study help establish whether PD providers in Beirut are basing their training programs on teachers' needs or on other aspects. Thus, Lebanese teachers can benefit from this research in specifying their needs and for Lebanese consultants in developing the appropriate PD sessions/programs. Also, this study will be the baseline for other research studies on this topic in the future.

\subsection{Definition of Key Terms}

Educational Consultancy (EC): Kilminster et al. (2007) defined educational consultancy as the provision of guidance and feedback on matters of personal, professional and educational development in the context of trainee's experience taking place (as cited in Hismanoglu \& Hismanoglu, 2010, p. 18).

Professional Development: The term professional development according to Sabah, Fayez, Alshmarani and Mansour (2014) is used to describe all the activities in which teachers are involved in during the course of their career, which are intended to improve their work, such as "attending internal and external courses and conferences, coaching and mentoring, joining PD networks, participating in reflective discussions, and conducting action research" (The Training and Development Agency TDA, 2007, p. 4).

\section{Literature Review}

The review of the literature will focus on teachers' perceptions of their needs for professional development, and the importance of conducting professional development for teachers, principals and schools, and the role of educational consultancy in teachers' PD.

According to OECD (2009), schools' expectations and performance are changing and so is what is expected of teachers. In fact, "teachers are asked to implement multicultural classrooms; to place greater emphasis on integrating students with special learning needs in their classrooms; to make more effective use of information and communication technologies for teaching; to engage more in planning within evaluative and accountability frameworks; and to do more to involve parents in schools" (OECD, 2009, p. 49). In the article "Creating Effective Professional Learning System to Bolster Teaching Quality and Student Achievement", Hirshi reports that educators' professional learning improvement is a critical step in schools' reformation and academic achievements (As cited in Wei, Hammond, Andree, Richardson, \& Orphanos, 2009, p. 2). The author also claimed that education consulting firms, policy makers, researchers, and school leaders provide schools with a teacher-development research base that can lead to effective professional learning, instructional improvement, and student performance. Over the years, millions of teachers participated in some form of professional learning or professional development. These activities include workshops, study groups, mentoring experiences, opportunities to view other teachers' classrooms, and numerous other formal and informal learning experiences. Moreover, findings of research by Fullan (2007) on teacher learning showed that continuous professional development of teachers is vital for improving the quality of education, and this has resulted in a profound interest by educational consultants and PD providers in activities supporting teachers' professional learning and development (as cited in Corte et al., 2013, p. 3).

\subsection{The Importance of Teachers' Professional Development}

In the article "Making Sense of the Links in Professional Development, Teacher Practices, and Student Achievement", Wallace (2009) claims that improvement in teacher learning, classroom practices, and student learning is the proposed goal for most professional development programs and that these goals are interrelated. Some PD programs meet teachers' expectations while others do not. For example, some schools provide their teachers with a needs' assessment plan in a certain academic year in order to assess their needs for the next 
academic year, and check whether the teachers have expectations regarding new learning and teaching improvements. However, in some schools, due to their lack of research and unstructured system, these assessments and expectations are not met. Paik et al. (2011) examined in their study the impact of a professional development program for K-12 science teachers on assisting teachers to meet state curriculum standards. The study was conducted on a 2-week summer workshop for 75 science teachers that focused on problem-based learning for improving teachers' content knowledge and pedagogical content knowledge. The results of this study showed that teachers who participate in the workshop were expected to learn new instructional strategies, improve content knowledge, and become more familiar with state curriculum standards, and their expectations were met due to a structured and systematic PD tool for improving teachers' quality and students' achievement. However, these studies examined the instructional strategies or content knowledge presented by PD providers rather than the teachers' own expectations and actual PD needs. Moreover, the PBL method was successful in providing teachers with learning opportunities in terms of standards-based teaching, which is closely related to implementing state curriculum standards. It was also found that teachers' readiness for standards-based teaching was generally improved (e.g., teachers' consideration of students' understanding and learning strategies), and this result was also assured by previous studies. Therefore, this study argued that professional development providers (educational consultancies) should meet higher objectives of the PD programs.

In a similar manner, Cuban (1990) reported that teachers are at the center of reform, for they must carry out the loads of high standards in the classroom. This means that policymakers, school principals, and educators should exert an effort in improving "the what" and "the how" of students' learning. As a result, teacher professional development is a major focus of complete reform initiatives.

To improve professional development, it is more important to focus on the duration, collective participation, and the core features of the professional development activities (content, active learning, and consistency) than on the type which is in contrary to teachers' perceptions. A study by Garet et al. (2001) investigated the relationship between structures of professional development that have been recognized in the literature for their success and self-reported changes in teachers' knowledge and skills and classroom teaching practices. This study was conducted with a sample of 1027 mathematics and science teachers, who presented experiential evaluation of the different characteristics' effects of professional development on teachers' learning. The results of the study showed that the three core qualities of professional development activities have significant positive effects on teachers' self-reported knowledge and skills and changes in classroom practice. Therefore, through these core features, the following structural features (the form of the activity, the participants, and the duration) significantly affect teacher learning.

\subsection{How Teachers Perceive PD}

All agree that what is more important than teachers' PD is how teachers perceive their needs for PD. Matteson et al. (2013) claimed that teacher professional development is most effective when it is designed based on teachers' needs. In their study, they provided information on topics that 53 middle/secondary level mathematics teachers considered would be helpful in future training programs. The teachers participated in a 2-year training program; also, professional development themes (time, resources, presentation opportunities, future training topics, and other) were identified from interviews conducted with 14 participants. The result of this study showed that both middle-school and high-school mathematics teachers were interested in PD that focused on meeting the needs of diverse student populations, resources, pedagogical uses of technology, providing more time to examine technology-focused activities, and learning from peers through the sharing of lessons. In other words, the PD program offered to them satisfied teachers' expectations and needs and ensured the growth of learning system. In addition, the teachers reported that the PD they had received was effective in regard to teaching specific student populations; however, future PD sessions are needed that focus on the instructional strategies of low-performing and learning-disabled students.

On the other hand, due to state mandated educational changes in Qatar, a study by Nasser and Romanowski (2011) examined teachers' perceptions of professional development as well as identified its challenges. Findings showed that the teachers believed that there was repetition in the workshops' content and lack of consultation with them on their needs. Teachers reported that the workshops were important for new teachers but not effective/useful for those who have more than 10 years of teaching experience and the method of the PD provided did not address the basic challenges of classroom teaching faced by teachers with students and workload. Therefore, Nasser and Romanowski (2011) argued that there is a need to adapt new PD programs with teachers that are more actively involved in the process of training and take into consideration their own perceptions on the needs of professional development. 
A study by Corte, Brok, Kamp and Bergen (2013) provides an understanding of participants' (e.g., school principals, teachers and student teachers) perceptions of the actual and preferred situation in terms of practice-based research as PD at a Dutch school. Results showed that a main difference exists between perceptions of the actual and preferred state relevant to the effects of teacher research on students' outcomes. In other words, the difference between the actual and the preferred professional development program was obvious, and having teachers as researchers can benefit the whole school system and supports the environment which in return can generate desired results.

\subsection{Comparing the Needs of Teachers to What Is Available to Them Through Different Agencies}

In conducting a professional development program, the provider must give much attention to the organization of the session, the content and strategies that will be implemented, and the measuring process of program impact on teachers. In summary, Alshamrani et al. (2014) stated that the knowledge, skills, and method of providing professional development could affect the success of any PD experience either positively or negatively. In this case, providers should offer a well-planned PD program that ensures its effectiveness.

In 2012, Burkman reported that, "educators and administrators must create the structures and culture that enable teachers to continue learning in and from practice as they address the complex challenges of public education" ( $p$. 24). Hence, PD providers and agencies should support teachers in their training to face the challenges they are exposed to in the educational field and in the schools' different environments. Furthermore, the induction program should be included in the professional development support systems tailored to teachers' needs, years of service, and experiences. Thus, developers of professional development programs must take into consideration the responsibilities and the needs of novice and experienced teachers and that too much professional development can be ineffective as too little; a balanced well-equipped professional development plan with continuous follow-up sessions is fundamental.

In summary, perceptions of teachers' needs for PD have not been discussed extensively in studies of educational consultancy. Hargreaves and Fullan (1992) argued that teachers couldn't ignore professional growth, as it advances educational standards, which revolve around the subject of providing equal and suitable opportunities for everybody. Unfortunately, there is ample information on PD but not enough on the match between PD needs and what's offered to teachers. Therefore, Hargreaves and Fullan (1992) emphasized that teachers need to continually equip themselves with the knowledge and skills needed to improve efficient opportunities for their students, assess their needs, and match them with PD workshops provided. Hence, Hismanal and Hismanal (2010) suggested that these processes can be done through educational consultancies, by integrating different knowledge and skills to create positive perceptions on teaching atmosphere.

\section{Methodology}

The following section explains the design of the study and the instruments that were used to collect data. Methods of analyzing the data of the study are also discussed. This study aimed to investigate the discrepancy between the perceptions of one EC and teachers on teachers' needs regarding professional development in one private school in Beirut. To reach these purposes, a mixed-methods design was used for this study, which involves the use of both qualitative and quantitative methods. This type of research is useful because "the use of both methods provides a more complete understanding of research problems than does the use of either approach alone" (Fraenkel, Hyun, \& Wallen, 2012, p. 557). Moreover, this mixed-methods study helped the researcher to confirm the similarities and differences that are discovered between teachers' perceptions and educational consultants' perceptions, as both quantitative and qualitative data were collected at the same time. However, the primary methodology was qualitative, with a lesser emphasis on the quantitative part. To explore consultants' views on teachers' $\mathrm{PD}$, one main instrument was used to collect data: an online semi-structured interview and it was used to address the second sub research question. This interview consisted of 10 questions that were emailed to one educational consultant in Lebanon, to obtain information that was later on compared and contrasted with the data from teachers. Moreover, a questionnaire was used to answer the first sub-research question and was distributed to teachers, to elicit perceptions of their current professional development needs and their needs for the next year. Items for the teachers' questionnaire and interviews with consultants were derived from the main research question and the reviewed literature.

\subsection{Participants and Sampling}

A convenience sample was selected for the study from the educational consultancy agency that the researcher works for in Beirut. A convenience sample according to Fraenkel et al. (2012) is a "group of individuals who conveniently are available for the study" (p. 99). In this study, one senior consultant was available for an online interview (see Appendix B). 
Moreover, purposive sampling was used in the study "based on a previous knowledge that the sample selected would be representative of the population" (Fraenkel et al., 2012, p. 100). In other words, based on the researcher's prior information, the participating teachers from this particular school provided the data needed, since they were trained by the educational consultancy firm that was mentioned in this study. Therefore, a questionnaire (see Appendix A) was distributed to 20 pre/lower elementary schoolteachers in a school that recently offered them professional development conducted by the educational consultant in this study.

\subsection{Instrumentation}

Two main instruments were used to accomplish this research: a survey questionnaire and a semi-structured interview. The main reason why these two instruments were used is because this combination "allows for a holistic interpretation of the phenomenon being investigated" (Merriam, 1998, p. 111). In other words, the data collected using these instruments helped investigate whether there is a discrepancy between EC and teachers' perceptions regarding teachers' needs of PD.

\subsubsection{Teacher PD Survey Questionnaire}

The aim of the survey was to acquire abundant detailed information from a large sample of individuals who have different perspectives. The questionnaire was constituted of 15 questions, some of which were based on a Likert-Scale, where teachers are required to read and evaluate the questions and statements attentively before they respond (Fraenkel et al., 2012). Other questions were open-ended (12 questions) and were related to teachers' expectations, discrepancies, and needs assessment of the professional development programs offered to them in school by the educational consultant.

The questions in the survey were constructed to comprehensively answer the first sub research question- - "How do teachers perceive their needs for PD?" Moreover, the survey was adopted from a website called 'Sogosurvey' (http://www.sogosurvey.com/survey.aspx?k=YsWUYTsYR), with some changes.

In order to increase the validity and reliability of the instruments, the survey was piloted before it was administered. It was distributed to some teachers the researcher knows (colleagues at the university and at the educational consultancy firm where she works). According to Fraenkel et al. (2012) "piloting is necessary to insure validity and appropriateness of the survey." Furthermore, in order to collect rich and accurate information, the data were collected after several PD sessions were offered by the EC for teachers. The participants were very helpful and answered all the questions.

This survey covered areas such as 21 st Century skills, classroom management, collaborative teaching, pedagogy, curriculum mapping, differentiated instruction, grading rubrics, leadership development, school culture, technology integration, and assessments. Also, it covered areas such as discrepancy between their needs and what is offered to them, delivery formats and preferences of training schedule.

\subsubsection{Semi-Structured Email Online Interview}

The literature defines email interview as a technique where two people (the researcher and the participant) discuss a specific topic under the supervision of the interviewer (Fraenkel et al., 2012). Interviews allow us "to obtain a special kind of information" (Merriam, 1998, p. 71) and are considered to be the "major source of the qualitative data needed for understanding the phenomenon under study" (Merriam, 1998, p. 91). In this case, email interviews give the participants enough time to think and respond to the questions, as it will save cost and time of the travel to conduct face-to-face interviews. This instrument was chosen in this study so that the educational consultant can explain the importance of his work.

The interview questions addressed the second sub-research question "How do educational consultants prepare for PD sessions/programs?" They were also derived from the survey questionnaire. The aim of this was to relate both instruments to each other and rephrase the survey questions in a more open-ended way. After the interview was conducted, the answers collected from it were compared with the answers collected from the survey.

The interview questions covered the services of these EC firms to schools, their role of designing and developing programs, their perceptions on teachers' needs of professional development, the follow up and monitoring system they use with teachers in the implementation of new programs, the discrepancy they face between teachers' needs, the delivery formats and time schedules they offer, their (EC) qualifications, years of experience in the field, and personal and informational background.

The interview questions were emailed to the educational consultant, and then the responses were documented for future analysis. 


\subsection{Reliability and Validity}

Using a variety of instruments and similar areas of questions to collect data, in addition to the consistency in results of the participants' responses ensured the reliability and the validity of the study. The validity of the study has been defined as the appropriateness, correctness, and usefulness of a specific conclusion that researchers draw based on the data they collect (Fraenkel et al., 2012). Furthermore, Merriam (1998) explained, "reliability in a research design is based on the assumption that there is a single reality and that studying it repeatedly will yield the same results" (p. 205). Thus, the first and second research sub-questions addressed teachers' perceptions and needs as well as consultants' PD preparations. This helped discover related and similar questions/areas/themes in the survey questionnaire and in the interview, to increase the reliability of this study. For example, question number two in the teachers' questionnaire that asked the teachers to rate some statements regarding PD sessions, gave insight on how teachers perceived and experienced these PD sessions. It is similar to the third question of the consultants' interview that asked them to rate teachers' experiences after their PD offering. This similarity was also applied to question number six of the teachers' questionnaire and question number nine of consultants' interview that asked them about the follow-up and monitoring processes. Regarding assessing teachers' needs for professional development, teachers' questions number eight (Appendix A) and consultant's questions number one, two, and four (see Appendix B) had similar areas of focus, to meet the consistency of the two research sub-questions. Moreover, questions number five, ten and eleven in Appendix A and questions number six and seven in Appendix B showed whether teachers' and consultants' preferences of PD delivery formats and training schedule are similar or different. Finally, question seven in Appendix A and question five in Appendix B showed whether there is a discrepancy between both EC and PD perceptions as they answered the main research question. Similarly, question three in the questionnaire and question eight in the interview answered the main research question of this study.

Therefore, the two research sub-questions and Appendix A and B helped answering the main research question of this study.

Table 1 . The reliability and the validity of the research instruments

\begin{tabular}{|c|c|c|c|}
\hline Study Purpose & Research Questions & $\begin{array}{l}\text { Questionnaire Items } \\
\text { (Appendix A) }\end{array}$ & $\begin{array}{l}\text { Interview Question } \\
\text { (Appendix B) }\end{array}$ \\
\hline $\begin{array}{l}\text { The purpose of the study is to } \\
\text { investigate whether there is a } \\
\text { discrepancy between the } \\
\text { perceptions of one PD provider } \\
\text { (educational consultancy) and } \\
\text { those of teachers in one school } \\
\text { in Beirut around teachers' needs } \\
\text { for PD. }\end{array}$ & $\begin{array}{l}\text { 1) How do teachers perceive their needs } \\
\text { for PD? } \\
\text { 2) How do educational consultants } \\
\text { prepare for PD sessions/programs? } \\
\text { 3) Is there a discrepancy between the } \\
\text { perceptions of educational consultants } \\
\text { and those of teachers around teachers' } \\
\text { PD needs? }\end{array}$ & $\begin{array}{l}\rightarrow \text { question \# } 2 \text { and } 4 \\
\rightarrow \text { question \# } 9 \\
\rightarrow \text { question \#6 } \\
\rightarrow \text { questions \# } 8 \\
\rightarrow \text { questions \# 5,10 and } 11 \\
\rightarrow \text { question \# } 7 \\
\rightarrow \text { question \# } 3\end{array}$ & $\begin{array}{l}\rightarrow \text { question \#3 } \\
\rightarrow \text { question \# } 9 \\
\rightarrow \text { questions \# 1,2 and } 4 \\
\rightarrow \text { questions \# } 6 \text { and } 7 \\
\rightarrow \text { question \# } 5 \\
\rightarrow \text { question \# } 8\end{array}$ \\
\hline
\end{tabular}

\subsection{Procedures}

First, the necessary approvals for conducting this study were obtained. Such approvals ensured that the researcher followed international and national ethical research standards, such as providing the participants with a written letter explaining to them the aim of the study and ensuring their confidentiality and anonymity.

\subsection{Data-Analysis}

After collection of data from the survey-questionnaire and the interview questions, a qualitative analysis of the interview and a quantitative analysis of the questionnaire were conducted.

Regarding the quantitative analysis, it was measured along a Likert scale that indicated how much teachers are familiar and have interest in some PD topics. According to Fraenkel et al. (2012), "quantitative data are obtained when the variable being studied is measured along a scale that indicates how much the variable is present" (p. 188). The respondents' details were entered into an Excel sheet and their responses were calculated in percentages.

As for the qualitative data, was reduced, analyzed, and synthesized the information that was obtained from the interview into a coherent description, that consisted of direct quotations from the participants about their experiences and opinions (Fraenkel et al., 2012; Merriam, 1998). Then, the data from both instruments were gathered and compared with similarities and differences being highlighted. 


\section{Results of the Study}

This section consists of two main parts that represent the results of the study. The first part includes analysis results of the data collected from the questionnaire (Appendix A). The second part includes an analysis of the EC interview (Appendix B).

\subsection{Analysis of the Questionnaire}

This section includes four parts. The first part (i) includes a description of the participants' personal information such as their university degree, grade level they teach, years of teaching experience etc. (questions 1,12 to 15 ). The second part (ii) shows the participants' attitudes concerning PD delivery format and time schedule of trainings (questions 10 and 11). The third (iii) part presents a qualitative analysis of the open-ended questions in the questionnaire $(3,5,6,7,9)$, concerning discrepancy, needs' assessment and follow-up regarding PD. Finally, part four (iv) shows the level of familiarity concerning areas in PD and level of interest in learning more about areas of PD (question 2 and 8), and the quality of PD courses that the teachers had attended (question 4).

i. In the questionnaire, teachers had been asked about the professional development courses they have attended, subject areas of teaching, grade level they teach, highest university degree they have earned, and years of teaching experience. Based on questions number 12,13,14, and 15, all the teachers at this school held a university undergraduate degree either in education, or in Arabic literature, English literature, biochemistry, or a postgraduate degree M.A in education, or a teaching diploma and many others. These teachers have teaching experiences rating from one to twelve years. Moreover, the teachers of this school teach preschool students and lower elementary students in a variety of subject areas such as, Arabic language, English language, arts, math, sciences, Islamic studies etc.

Regarding question number one, $100 \%$ of the teachers answered that they had attended more than five professional development courses.

ii. Tables 3 and 4 illustrate the results of questions number 10 and 11 regarding teachers' interests in PD delivery format and preference for training schedules. Using Table 3,50\% of the teachers were interested in the class observation delivery format, while the others were not. $45 \%$ of the teachers were interested in computer-based training, however, a higher percentage (55\%) were not interested in this form of PD delivery format. Moreover, $45 \%$ of the teachers were interested in hands-on participation. The remaining $55 \%$ were not interested in it. Regarding series of topic related workshops, $60 \%$ of the teachers were interested in it, however, a lesser percentage $(40 \%)$ were not interested in this type of delivery format. When teachers were asked about job-embedded training (connecting the actual work to students' work), a small percentage (35\%) were interested, while $60 \%$ were not at all. Concerning training format by inspiring stories, $60 \%$ were interested, and $40 \%$ were not interested. As for the case study format, $60 \%$ were interested, however $40 \%$ were not. Also, $60 \%$ of the teachers were interested in team bonding activities, and $40 \%$ were not. Finally, when the teachers were asked about "forum: discussion and debate" delivery format, $55 \%$ were interested while $45 \%$ showed no interest. $65 \%$ of teachers prefer their training sessions to be before first day of school for students and on school calendar days; $25 \%$ of the teachers believe the best timing is on school calendar days and training that is job embedded. However, only $10 \%$ preferred to have their trainings either on Saturdays or on school calendar days. None of the teachers $(0 \%)$ preferred to have their trainings during summer or spring breaks.

Table 2. PD delivery format

\begin{tabular}{llll}
\hline Question 10 & Interested & Not interested & Total \\
\hline In-Class observation & 50 & 50 & 100 \\
Computer-Based Training & 45 & 55 & 100 \\
Hands-on Participation & 45 & 55 & 100 \\
Series of topic-related workshops & 60 & 40 & 100 \\
Job-Embedded & 35 & 65 & 100 \\
Inspiring stories & 60 & 40 & 100 \\
Case Study & 60 & 40 & 100 \\
Team bonding activities & 60 & 40 & 100 \\
Forum: discussion and debate & 55 & 45 & 100 \\
\hline
\end{tabular}

iii. This part consists of open-ended questions related to teachers' PD needs' assessment, PD program improvement, consultant's follow-up and monitoring processes, discrepancy faced in PD programs, and more PD interesting topics. 
Table 3. PD delivery format

\begin{tabular}{llll}
\hline Question 10 & Interested & Not interested & Total \\
\hline In - Class observation & 50 & 50 & 100 \\
Computer- Based Training & 45 & 55 & 100 \\
Hands- on Participation & 45 & 55 & 100 \\
Series of topic related workshops & 60 & 40 & 100 \\
Job- Embedded & 35 & 65 & 100 \\
Inspiring stories & 60 & 40 & 100 \\
Case Study & 60 & 40 & 100 \\
Team bonding activities & 60 & 40 & 100 \\
Forum: discussion and debate & 55 & 45 & 100 \\
\hline
\end{tabular}

Table 4. PD training schedule

\begin{tabular}{lcccccc}
\hline & a & b & c & d & e & f \\
\hline question 11 & $65 \%$ & $65 \%$ & & & & \\
& & $25 \%$ & & & & \\
& & $10 \%$ & $10 \%$ & & & \\
\hline
\end{tabular}

Table 5, illustrates whether teachers' PD needs had been assessed before the PD course was offered. This table shows that the majority $(90 \%)$ of teachers' needs had not been assessed, with only $10 \%$ of the teachers having had their PD needs assessed. The $10 \%$ of teachers who said that their needs had been assessed were new teachers and they had to read and practice the school's new curriculum. Also, one of the teachers was a math teacher and her needs were assessed in a math development course.

Table 5. PD needs assessment

\begin{tabular}{llll}
\hline & yes & No & Total \\
\hline question $\mathbf{3}$ & $10 \%$ & $90 \%$ & $\mathbf{1 0 0 \%}$ \\
\hline
\end{tabular}

Table 6, illustrates whether the teachers faced any discrepancy between what they had perceived of PD and what was offered to them by the educational consultant. Results show that $85 \%$ of teachers did not face any discrepancy, while the remaining $(15 \%)$ reported that they sometimes did.

Table 6. Teachers' discrepancies

\begin{tabular}{lllll}
\hline & yes & No & sometimes & Total \\
\hline question 7 & $0 \%$ & $85 \%$ & $15 \%$ & $\mathbf{1 0 0 \%}$ \\
\hline
\end{tabular}

Regarding question five, when teachers were asked about their opinion on PD program improvements, the answers were different. Some of the teachers reported that the main improvements should happen by research, while others believed that most of the courses should be related to the grade level, subject areas, needs of the teacher, analyzing cases and problems rather than dealing with theoretical issues. Many teachers believed that with more interactive courses, and by providing more examples about the materials that they explain, PD improvement will take place as well as teachers' improvement. Nevertheless, some teachers showed a high interest in applying PD sessions directly with students, which could make them more student-centeredworkshops. In addition to that, some teachers thought of receiving training/mentoring from the teachers in higher grades and by observing them in their classes. Some teachers wanted more engaging and practical programs, while others asked to discuss their experiences with other teachers.

Concerning question 5, when teachers were asked about the educational consultant's follow-up and monitoring processes, most of the teachers showed that there was always follow-ups and monitoring process. Also, some teachers said that the follow-up process was monthly and continuous. However, several teachers wrote that the curriculum coordinator always give them tips, sends emails including resources related to PD to ensure teachers' learning and program implementation. Moreover, some said that after each course, the curriculum coordinator monitors and views their work through class, to ensure all program and activities are being implemented in the class. 
Furthermore, question 9 asked teachers about their interests in PD topics other than the topics listed in the questionnaire items. After collecting responses, results showed teachers' interests in PD topics such as, accent development, language policies, child psychology, dealing with gifted and talented students, interactive resources activities, emotional intelligence guidance, and shifting mental models in education. However, most of the teachers believed that the topics listed were enough.

iv. This part shows the level of familiarity concerning areas in PD and levels of interest in learning more about areas of PD (question 8). Also, this part shows the results of the quality of the PD sessions that the teachers have attended this year (question 4), and their rates on some statements regarding PD sessions (question 2).

Moreover, the results obtained from teachers' familiarity and interest in some PD topics listed in the questionnaire (see Appendices C and D). $40 \%$ of the teachers have high familiarity with 21 st Century learning skills, with $75 \%$ of teachers showing strong interest in them. The same results were evident in the topic of classroom management. Moreover, teachers demonstrated moderate familiarity with collaborative teaching, with a rate of $55 \%$, and $40 \%$ of the teachers showed that they have high familiarity, with a small percentage (5\%) showed limited familiarity. $70 \%$ of the teachers showed strong interest in collaborative teaching, $10 \%$ moderate interest, and $20 \%$ little interest. $25 \%$ of the teachers showed high familiarity with curriculum mapping/reading across the curriculum and $80 \%$ of teachers showed strong interest in this topic to learn more about. Considering differentiated instruction, $5 \%$ of teachers showed high familiarity with this topic and $60 \%$ have strong interest in it and are ready to learn about it. $30 \%$ of the teachers were highly familiar with leadership development. Also, $75 \%$ of the teachers showed a strong interest in leadership development and wanted to learn more. Furthermore, 55\% of the teachers claimed that they had moderate familiarity with technology integration, $40 \%$ high familiarity, and only 5\% limited familiarity. Although, high percentages showed familiarity with technology integration, still 55\% showed a strong interest in learning more about it, with $35 \%$ and $10 \%$ moderate and little interest respectively. Some of the teachers $(40 \%)$ showed high familiarity with self-awareness and improvement as a PD topic, with a very high percentage $(85 \%)$ showing a strong interest in this topic. Concerning organizational behavior, overcoming obstacles in education, and character education and development, $55 \%, 85 \%$, and $80 \%$ of teachers respectively have moderate familiarity. Whereas, $50 \%, 60 \%$, and $80 \%$ respectively, showed a strong interest in the above PD topics.

The interview illustrates teachers' rates on some statements regarding PD sessions. In addition to that, $75 \%$ of the teachers strongly agree and $25 \%$ agree that the professional development course content that had been offered to them was relevant to their current job functions. $80 \%$ of teachers strongly agree that the professional development courses that they had attended have helped them do their job better. Moreover, $75 \%$ of the teachers strongly agree that the professional development courses that they had attended have helped their students in the classroom. Whereas, $70 \%$ of the teachers strongly agree that the professional development courses have helped them prepare for advancement.

Furthermore, the results of the teachers' grades on the quality of the PD sessions that they had attended this year. $50 \%$ of teachers gave an "A" outstanding grade, $45 \%$ gave " $\mathrm{B}$ ", and only $5 \%$ of the teachers gave a "C" as an average grade. None of the teachers $(0 \%)$ stated that the PD course was a failure.

\subsection{Analysis of the Interview}

The interview was designed for one educational consultant in Lebanon. The interview addressed the perceptions of EC firms regarding teachers' needs for professional development. The interview questions were semi-structured. The questions of the interview were sent by email to the EC, and the researcher received the answers back after three days. The interview questions were clear to the educational consultant, so he answered all the questions without any further explanation.

The consultant holds an M.A in educational management and leadership from a private university. He was the Dean of Students and Assistant to Development and HR Director at a private school. As of 2008, he started conducting PD programs for schools, NGOs, and educational centers and facilities in Lebanon, Jordan, and the Gulf countries. Now, he is the founder and the managing director of an educational management and youth leadership consultancy firm.

The first question of the interview asked the consultant about his plan for PD sessions, and about the factors that he takes into consideration when planning sessions. The consultant stated that the most important element in planning for PD sessions is the identification of the educational establishment's needs by scheduling different meetings with the school administration, and by planning a field visit if possible. Moreover, the consultant claimed that "we want to learn more about the culture of the school, the policies and procedures in place, what's working and what's not, major achievements, and what they identify as major gaps and challenges." He also said 
that, as an EC agency, they want to inquire about previous training and workshops that the teaching faculty and staff had participated in, and the effect of such interventions on their current practices. In this case, this information helps the EC understand the environment he will be working on, plan proactively, and customize the PD program to meet the real needs of the environment and its participants. Regarding how the professional development sessions are selected and by who, the EC believes that offering a pre-packaged formula and applying it to every educational establishment's situation, is not their case as PD providers. Yet, he stated that they work closely with the school leadership team to understand their needs and adapt their (EC) services to the school. This means that they sit with the leadership team on different think tank meetings and together (the school and the consultant) come up with a final list of PD urgent/important priorities. He explained that the process goes as follows, "upon understanding the school culture, system, performance, strengths, weaknesses, opportunities, and threats, we share with the leadership team the areas of development we believe are important for the school to undergo."

Considering the question about teachers' experiences and expectations of the PD sessions offered to them, the consultant commented that in one school they served, they had to develop and lead a supervisors' capacity building program for a group of participants of ages 35 to 60 with an average of 12 years of experience per participants. He claimed that this helped them design a PD program that starts from sharing the participants' vast educational experience. Therefore, he ended up his response by arguing that the participants were extremely excited during the PD program. During the interview, the researcher was curious to know whether what was offered to teachers was also interesting to them. Thus, the researcher asked the consultant about the most frequent PD offerings they provide or organize. The consultant proposed more than 20 PD topics; however, he stressed teacher leadership, character education and development, 21 st century skills, building effective teams and managing conflicts, organizational behavior, overcoming obstacles in education, self-awareness and improvement and many others.

Furthermore, the consultant was asked about the strategies or the PD delivery format; he reported that they use a wide range of activities and games that have the power to bring everyone in. Hence, he focused on inspiring stories, short clips, team bonding activities, case studies, forum discussion and debate, and games and songs. In addition to that, he said that they design a 1 or 2-year plan, and in many cases, they organize a couple of 1 to 2-day PD program, as per the school's preference timing schedule, either on breaks or during school calendar days.

Another important question was asked to the consultant about the discrepancy they face between teachers' perceptions of PD and what they offer to them for PD. He stated that they never faced any issue with teachers' perceptions of what they offer as PD; however, they have faced a discrepancy between the EC's PD sessions and how teachers actually describe the school's operations, policies, and procedures; as, the description was not well-aligned with what the EC firm was doing. A second discrepancy involved the inability of some teachers to accept PD and the need to develop and grow professionally. The EC explained about these teachers by stating that, "they are either some old aged teachers who are not ready to sit and learn about how they can improve their performance and acquire new knowledge, or young teachers who are not motivated enough to sit for PD sessions after school, on weekends, or during holiday." The third and final discrepancy is related to the absence of a clear professional development scheme at the school level. For example, the EC explained that when the school doesn't have a clear professional development rationale, profile, and plan for the teaching faculty and staff, PD then becomes a luxury, a burden, and not a necessity.

Moreover, the researcher asked the consultant how the information is gathered about teachers' needs for PD. The EC explained that they rely on different meetings with the leadership team, field visits, meetings with different members of the teaching faculty and staff across the school's organizational chart, and they also collect a lot of relevant information when they are engaged and interacting with them. In addition to this, he stated that they might pass a questionnaire to the teaching faculty and staff that helps identify the school's PD priorities.

Finally, regarding the EC monitoring and follow-ups on the implementation of what teachers learn from PD activities, the EC can follow up for a full 1, 2, or 3 years only if the school signs a full consultancy agreement. In this way, the EC attend regular meetings to meet the mission of the school. However, he added that it's difficult to "monitor the quick PD shots" that schools schedule for their teaching faculty and staff throughout the school year; he added "we can support but we have no guarantee over what happens when we leave."

In short, the questionnaire showed that the PD programs that are offered to teachers are beneficial and meet teachers' expectations. Moreover, it showed that the PD programs are aligned with their needs with some mild differences. For example, teachers' needs assessment is not conducted for teachers as a prerequisite before the 
PD sessions. Also, several topics on PD that teachers have interest in are not provided. Regarding the interview, the consultant showed that he plans, organizes, and designs the PD programs upon teachers' needs and leadership team acceptance. Furthermore, the consultant gave evidence on several discrepancies he faced during teachers' PD, however, not with the PD itself, but with the school's system as a whole.

\section{Discussion of the Findings}

This study aimed at showing whether there is a discrepancy between the perceptions of the educational consultant and those of teachers in one school in Beirut concerning teachers' needs for PD. The importance of offering professional development programs by an educational consultancy is emphasized in this study to show its significance in providing such programs to prepare, train, and recruit high-quality teachers who meet with the 21 st century reformation.

In addressing the first research sub-question (i.e., How do teachers perceive their needs for PD?), results of the questionnaire (Appendix A) and those of the interview (Appendix B) were used to uncover the answer. Based on the questionnaire, all the teachers $(100 \%)$ were given more than five professional development training sessions by an educational consultant. This means that during this study, all the teachers were exposed to PD programs that can make the study more significant. Regarding question two in the questionnaire, when teachers were asked about their experiences and expectations of the PD quality, many of them expressed satisfaction with the PD course content offered to them and reported that the courses were helpful to them and to their students in the classrooms. Thus, most of the teachers gave an excellent evaluation of the quality of the PD courses. This means none of the teachers believed that their PD courses were a failure. The results of the same question in the interview showed that the teachers were extremely excited during the PD program and they felt that they were appreciated. The consultant starts up the PD session by noting down the teaching faculty and staff's expectations from the training, and it has always been an outstanding satisfaction. Hence, the results of the questions were very close, indicating that the PD is effective for teachers' quality education and that effective PD programs develop teachers' knowledge and skills, improve teaching practice, and raise learners' performance, as Steyn (2007) had stated.

Furthermore, when the teachers were asked about the educational consultant's follow-up and monitoring processes in question six (Appendix A), most of the teachers showed that there was always a follow-up and monitoring process, however, by the school's curriculum coordinator and not by the educational consultant. The curriculum coordinator gave teachers some tips, and sent emails that included resources related to PD, to ensure teachers' learning and program implementation. In contrast to the interview results of question nine, the consultant said that follow-ups happen only when the school leadership team assumes its full responsibility in following up on the right integration and the implementation of the plans. Moreover, the answers showed that the consulting agency can only follow up if the school signs a 2 to 3-year agreement, so then the agency can do regular meetings to serve the school's mission. However, results also showed that the follow-up meetings are not enough to guarantee what happens in the school. Therefore, the consultancy firm does not follow-up and monitor if their PD programs have been integrated and implemented in teachers' classrooms. Only the school leadership can do this, and that is not enough to ensure whether the PD provider is effective at schools. The need for continuing support and follow-up is a principle in the characteristics of effective PD programs, and to be effective, professional development should entail considerable planning followed by careful implementation with feedback to ensure it responds to educators' learning needs (Mizell, 2010).

Also, the results showed that most of the teachers have interest in topics such as accent development, language policies, child psychology, dealing with gifted and talented students, interactive resources activities, emotional intelligence guidance, and shifting mental models in education, but not all teachers' needs were perceived by the educational consultant. This means that not of the above topics are offered by the EC, as shown in the interview answers.

These findings show the need for studies on educational consultancies and teachers' perceptions of their PD needs (Alshamrani et al., 2014), and indicate that many schools provide their teachers with PD sessions; however, neither schools nor agencies/consultancies/PD providers effectively follow up and monitor teachers' work and implementation of the PD program.

In addressing the second research sub-question (i.e., How do educational consultants prepare for PD sessions/programs?), the questionnaire items $(5,8,10$, and 11) and the interview items $(1,2,4,6$, and 7$)$ were used to find the answer. Based on studies, many PD agencies that are for profit claim that they are preparing and offering PD sessions that are relevant to teachers' work and needs (Steyn, 2007), but no recent research shows how educational consultants prepare or organize their PD programs. According to Fayez, Alshamrani, and 
Mansour (2014), providers of knowledge and skills are the most influential in the success of any professional development experience. Therefore, based on the interview, when the consultant was asked about the planning for PD sessions and about the factors they take into consideration as a consultancy when they plan for PD sessions, he stated that the most important element in planning for their PD sessions is the educational establishment's needs. He also reported that as an EC agency, they inquire about previous training and workshops the teaching faculty and staff had participated in, and the effect of such interventions on their current practices. This was also evident in the interview question two when the consultant was asked about the selecting process of PD sessions, and the designing of PD programs. The answers showed that the consultant does not provide a pre-packaged formula, since, as he stated, they work closely with the school leadership team to understand teachers' needs and adapt their (EC) services to the school. Therefore, this interview information helps the EC to understand the environment he will be working on, plan proactively, and customize the PD program to meet the real need of the environment and its participants. In contrast, what was found from the questionnaire is that teachers' needs or ideas were not taken into consideration and no answer was found in the teachers' questionnaire responses that shows that the consultant sat and discussed with them all the aspects he mentioned in the interview.

Furthermore, two questions from the questionnaire and the interview were used to check whether there is consistency in results regarding the most frequent PD offerings/courses organized by the EC and teachers' familiarity with and interests in some PD topics. Based on the interview, the consultant stated that as an EC agency, they offer topics on teacher leadership, character education and development, 21 st Century student leadership and skills, leadership skills for the teaching faculty and staff, developing motivation among the school community, building effective teams and managing conflicts, identifying our 'why for teaching' and 'personal educational mission', self-awareness and improvement, organizational behavior, overcoming obstacles in education and many others. On the other hand, the results of the questionnaire showed that an average percentage of teachers have high familiarity with 21 st century skills, classroom management, collaborative teaching, curriculum mapping/reading across the curriculum, leadership skills, self-awareness and improvement and other topics. Even though, the teachers showed average familiarity with these topics, still many of them showed a very high rate of interest in learning more about such topics. Therefore, findings indicate that there are common topics provided from the EC to the teachers; however, teachers have the urge to learn more about such topics. This means there were differences between the EC offerings and the teachers' views and needs of PD.

Moreover, concerning the strategies and delivery format, and the preferences for training schedules, results showed that teachers are interested in class observation, computer-based training, and hands-on participation, with a lesser interest in job-embedded training. Concerning time schedule, teachers prefer their training sessions to be before the first day of school for students. Similarly, the consultant designsan interactive engaging sessions where all participants have the chance to think, reflect, cooperate, present, play, and have fun such as inspiring stories, team-bonding activities, forum discussion and debates and others. Also, findings showed that the teachers are interested in research, interactive activities, student-centered workshops, and what the PD provider is offering is relevant to teachers' interest in the delivery format and training schedule. This is also consistent with the scholarly literature since to improve $\mathrm{PD}$, research shows that it is more important to focus on the duration, collective participation, and the core features of the professional development activities (content, active learning, and consistency) than on the type, which is in contrast to teachers' perceptions (Cuban, 1990; Garet et al., 2001).

In other words, the PD topics and delivery format that are argued for in this study show that the teachers were satisfied and their expectations and needs ensure the growth of the learning system. Similarly, Alshamrani et al. (2014) claimed that the knowledge, skills, and method of providing professional development could affect the success of any PD experience either positively or negatively. In this case, providers should offer a well-planned interactive PD program that accomplishes success tailored to each school system.

In addressing the main research question of the study (i.e., Is there a discrepancy between the perceptions of educational consultants and those of teachers regarding teachers' PD needs?), the results showed that the majority of teachers' needs were not assessed and that the results are inconsistent with what the consultant had reported in the interview. Yet, there is general agreement that what is more important than teachers' PD is how teachers perceive their needs for PD. And this is relevant to the study conducted by Nasser and Romanowski (2011), in which teachers believed that there was repetition in the workshopsand many found that there is a lack of consultation with them on their needs. Similarly, the findings of this study indicate that the consultant does not take into consideration teachers' years of experience and their knowledge on the subject matter. This is supported by study findings by Nasser and Romanowski (2011), who found out that workshops may be 
important for new teachers but they might not be organized for those who have more than 10 years of teaching experience.

Moreover, results of whether the teachers faced any discrepancy between what they had perceived of PD and what was offered to them by the EC, show that teachers did not face any discrepancy. Whereas the consultant stated that the discrepancy faced is between EC's PD sessions and how teachers describe the school's operations, policies, and procedures. Another discrepancy they faced involved the inability of some teachers to accept PD and the need to develop and grow professionally. And the last discrepancy was the absence of a clear PD scheme at the school level.

Hence, it can be concluded from this that since the consultant actually faces these kinds of discrepancies, the teachers might not consider them as important. So, either the teachers did not understand the content of the question or as the consultant has said, the teachers lack the knowledge on how the overall system of the school works. Moreover, it was discovered that many teachers take the workshops sessions, conferences, and PD sessions only for luxury experiences to post them on their CVs, yet this can't be generalized to include all the teachers. Referring back to the literature, according to Burkman (2012), PD providers and agencies should support teachers in their trainings to face the challenges they are exposed to in the educational field and in the schools' different environments. Therefore, Hargreaves and Fullan (1992) suggested that teachers need to continually equip themselves with the knowledge and skills needed to improve efficient opportunities for their students and assess their needs and match them with PD workshops provided. This study shows that it is the consultant's responsibility to ensure this continuing development and growth.

\subsection{Conclusion}

This study revealed that there is a slight discrepancy between teachers' and consultant's perceptions on teachers' needs of professional development. This is due to the lack of communication between teachers and the consultant. More communication happens between the school leadership team and the consultant. In other words, both cannot ensure whether the courses they are offering are a success and a need for any subject teacher. Only teachers can tell what they need and how they perceive PD courses. However, the study also showed that the educational consultant is an active participant, who can provide direct and fruitful PD programs that cover all aspects and factors of an effective PD, and who is aware of what is happening around in the educational field. Therefore, we can conclude that the role of EC is having a huge impact and success in schools and can reduce the burden that schools put on their teachers to plan for their own PD.

\subsection{Limitations of the Study}

Although the participants are diverse from the same school and from one EC firm, yet they are not considered to be the representatives of all the teachers and consulting firms in Beirut.

Another limitation is restricting the study to only one private school in Beirut. Thus, the results of the study cannot be generalized.

\section{References}

Austin, D. (2010). Introducing consultancy supervision in a primary school for children with social, emotional and behavioral difficulties. Emotional and Behavioral Difficulties, 15(2), 125-139. https://doi.org/10.1080/13632752.2010.480882

Burkman, A. (2012). Preparing Novice Teachers for Success in Elementary Classrooms through Professional Development. The Delta Kappa Gamma Bulletin, 78(3), 23-33. Retrieved from http://web.a.ebscohost.com/ehost/pdfviewer/pdfviewer?vid=2\&sid=318cf6ae-b0d7-44a1-a71a-b50b54e793 $70 \% 40$ sessionmgr4002\&hid $=4207$

Corte, M. V., Brok, P., Kamp, M., \& Bergen, T. (2013). Teacher research in Dutch professional development schools: perceptions of the actual and preferred situation in terms of the context, process and outcomes of research. European Journal of Teacher Education, 36(1), 3-23. https://doi.org/10.1080/02619768.2012.662639

Fraenkel, J., Hyun, H., \& Wallen, N. (2012). How to Design and Evaluate Research in Education (8th ed.). New York, NY: The McGraw-Hill Companies.

Garet, M. S., Porter, A. C., Desimone, L., Birman, B. F., \& Yoon, K. S. (2001). What makes professional development effective? Results from a national sample of teachers. Journal of American Educational Research, 38(4), 915-945. https://doi.org/10.3102/00028312038004915

Hismanoglu, M., \& Hismanoglu, S. (2010). English language teachers' perceptions of educational supervision in 
relation to their professional development: A case study of northern Cyprus. Novitas Royal Research on Youth and Language, 4(1), 16-34. Retrieved from http://web.a.ebscohost.com/ehost/pdfviewer/pdfviewer?sid=318cf6ae-b0d7-44a1-a71a-b50b54e79370\%40s essionmgr4002\&vid $=10 \&$ hid $=4207$

Kolnik, K. K. (2010). Lifelong learning and the professional development of geography teachers: A View from Slovenia. Journal of Geography in Higher Education, 34(1), 53-58. Retrieved from http://web.a.ebscohost.com/ehost/pdfviewer/pdfviewer?sid=318cf6ae-b0d7-44a1-a71a-b50b54e79370\%40s essionmgr4002\&vid=13\&hid $=4207$.

Matteson, S., Ozel, S., \& Zientek, L. (2013). Identifying what in-service teachers want in professional development experiences. Teacher Education and Practice, 26(3). Retrieved from http://web.a.ebscohost.com/ehost/pdfviewer/pdfviewer?sid=318cf6ae-b0d7-44a1-a71a-b50b54e79370\%40s essionmgr4002\&vid $=16 \&$ hid $=4207$

Merriam, S. (1998). Qualitative research and case study applications in education (2nd ed.). San Francisco: Jossey-Bass.

Mizell, H. (2010). Why professional development matters. Retrieved fromhttp://www.learningforward.org

Nabhani, M., Nicolas, M., \& Bahous, R. (2013). Principals' views on teachers' professional development. Professional Development in Education, 1-14. https://doi.org/10.1080/19415257.2013.803999

Nasser, R., \& Romanowski, M. (2011). Teacher perceptions of professional development in the context of national educational reform: the case of Qatar. International Journey of Training and Development, 15(2), 158-167. https://doi.org/10.1111/j.1468-2419.2011.00377.x

Paik, S., Zhang, M., Lundeberg, M. A., Eberhardt, J., Shin, T. S., \& Zhang, T. (2011). Supporting Science Teachers in Alignment with State Curriculum Standards through Professional Development: Teachers' Preparedness, Expectations and their Fulfillment. Journal of Science Education Technology, 20, 422-434. https://doi.org/10.1007/s10956-011-9308-1

Penuel, W. R., Fishman, B. J., Yamaguchi, R., \& Gallagher, L. P. (2007). What Makes Professional Development Effective? Strategies that Foster Curriculum Implementation. Journal of American Educational Research, 44(4), 921-958. https://doi.org/10.3102/0002831207308221

Sabah, S., Fayez, M., Alshamrani, S., \& Mansour, N. (2014). Continuing Professional Development (CPD) Provision for Science And Mathematics Teachers in Saudi Arabia: Perceptions And Experiences Of CPD Providers. Journal of Batlic Science Education, 13(3), 91-104. Retrieved from http://web.a.ebscohost.com/ehost/pdfviewer/pdfviewer?vid=20\&sid=318cf6ae-b0d7-44a1-a71a-b50b54e79 $370 \% 40$ sessionmgr $4002 \&$ hid $=4207$

Steyn, M. (2007). Educators' perceptions of continuing professional development for teachers in South Africa: A qualitative study. Africa Education Review, 7(1), 156-179. Retrieved from http://web.a.ebscohost.com/ehost/pdfviewer/pdfviewer?vid=22\&sid=318cf6ae-b0d7-44a1-a71a-b50b54e79 $370 \% 40$ sessionmgr $4002 \&$ hid $=4207$

$\begin{array}{lllll}\text { Teacher Professional Development } & \text { Survey } & \text { (n.d.). Retrieved }\end{array}$

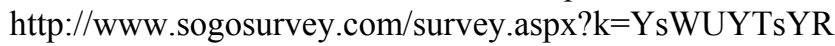

Wallace, M. R. (2009). Making sense of the links in professional development, teacher practices, and student achievement. Teachers College Record, 111(2), 1-13. Retrieved from http://www.tcrecord.org/library

Wei, R. C., Hammond, L. D., Andree, A., Richardson, N., \& Orphanos, S. (2009). Professional learning in the learning profession: A status report on teacher development in the U.S. and abroad. Retrieved from http://learningforward.org/docs/pdf/nsdcstudytechnicalreport2009.pdf?sfvrsn=0

\section{Appendix A}

\section{Teacher Professional Development Survey}

\section{RQ 1: How do teachers perceive their needs for PD?}

This survey is designed to identify staff professional development needs. The survey includes a short section that addresses perceptions of the current year professional development program and an extensive section to uncover needs for the next year's offerings. The survey is structured to be flexible to accommodate one school in Beirut. 


\section{Teacher Professional Development Survey}

\section{Dear Teacher,}

Professional development is essential in today's economy to ensure that workers have the knowledge and skills to compete in the global economy. That is, you need to have the most up-to-date skills and knowledge to help your students succeed. This survey is designed for you to give us feedback as to the topic areas where you need additional training. It covers areas such as classroom management, pedagogy, and assessment, among many others. The information you and your colleagues provide will be used to prepare a comprehensive professional development program. You will also help conduct my research study at the Lebanese American University.

1) How many professional development courses did you attend this year?

a. None

b. 1 or 2

c. 3 or 4

d. 5 or More

2) Please rate the following statements regarding PD sessions you took this year by checking one of the boxes to the right.

\begin{tabular}{|c|c|c|c|c|}
\hline & $\begin{array}{l}\text { Strongly } \\
\text { Agree }\end{array}$ & Agree & Disagree & $\begin{array}{l}\text { Strongly } \\
\text { disagree }\end{array}$ \\
\hline \multicolumn{5}{|l|}{$\begin{array}{l}\text { The professional development course content is relevant to my current job } \\
\text { functions. }\end{array}$} \\
\hline \multicolumn{5}{|l|}{$\begin{array}{l}\text { The professional development courses I have attended have helped me do } \\
\text { my job better. }\end{array}$} \\
\hline \multicolumn{5}{|l|}{$\begin{array}{l}\text { The professional development courses I have attended have helped me } \\
\text { better help my students in the classroom. }\end{array}$} \\
\hline $\begin{array}{l}\text { The professional development courses have helped me prepare for } \\
\text { advancement. }\end{array}$ & & & & \\
\hline
\end{tabular}

3) Have your professional development needs been assessed before you were offered the course? If yes indicate how?

4) Overall, what grade would you give for the quality of the professional development sessions that you attended this year? Please use the scale from $A$ to $F$, where " $A$ " is outstanding, " $C$ " is average, and " $F$ " is failure.

- $\mathrm{A}$

- $\mathrm{B}$

- $\mathrm{C}$

- $\mathrm{D}$

- $\mathrm{F}$

5) How can the professional development program be improved so that you give a higher grade next year?

6) How often does the consultant agency monitor or follow up with you after the PD session to ensure your learning and the implementation of the program?

7) Have you ever faced any discrepancy between what you perceive of PD and what is offered to you by educational consultant?

\section{8) Professional Development Needs Assessment}

Your answers to the following questions will help us to explore teachers' needs on professional development.

For each of the following items, please provide two ratings:

1) Please rate your level of familiarity concerning this area. Scale: Not Familiar, Limited Familiarity, Moderate Familiarity, High Familiarity.

2) Please rate your level of interest in learning more about this area. Scale: No Interest, Little Interest, Moderate Interest, Strong Interest. 
General Professional Development Topics

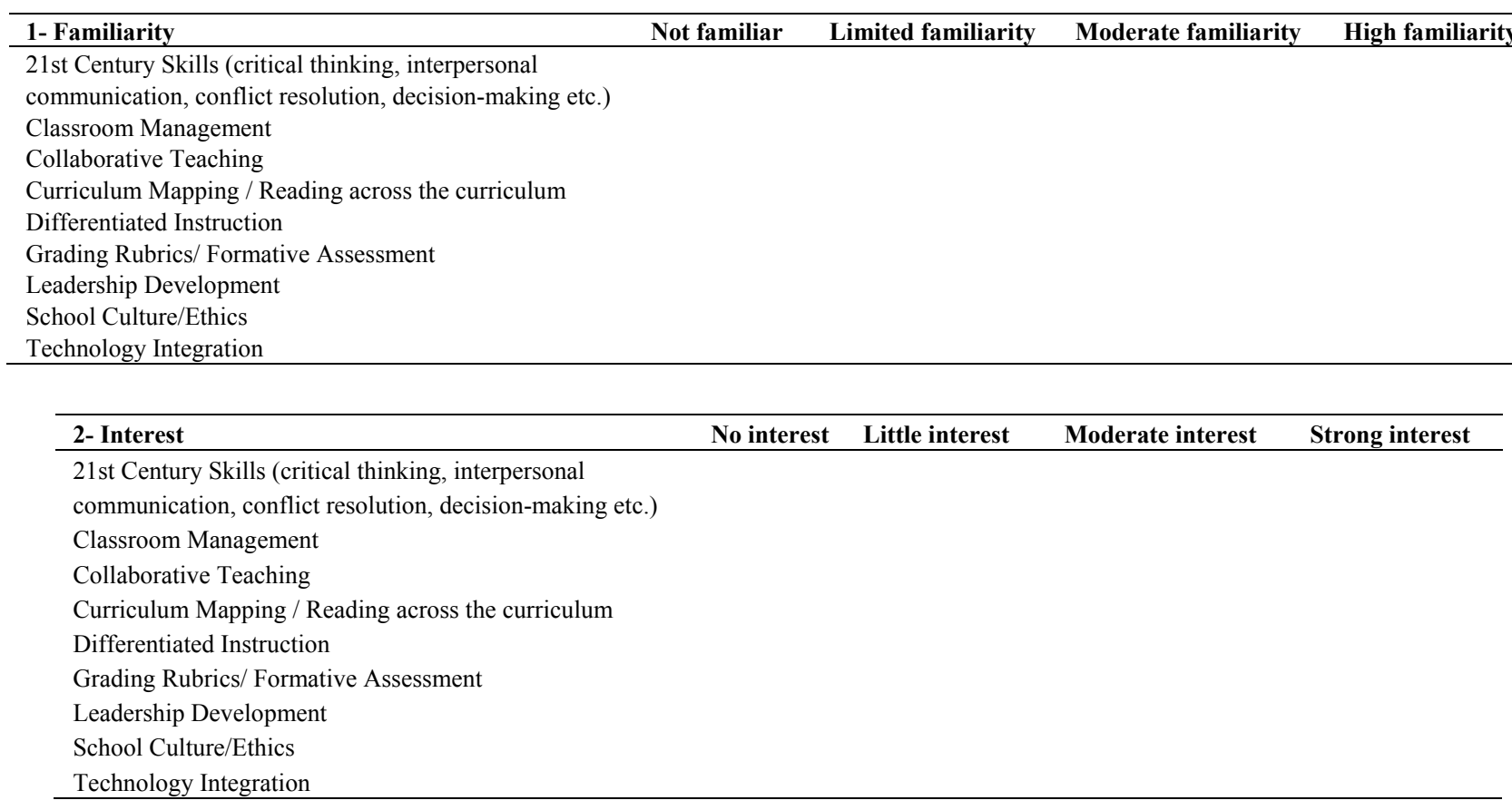

9) What other topics not listed above would you be interested in learning more about?

10) Write whether you are "interested" or "not interested" in each of the following PD format?

a. In-Class observation

b. Computer-based training

c. Hands-on participation

d. Series of topic related workshops

e. Job-Embedded (e.g., mentoring)

11) Please circle your preference for scheduling of training.

a. Before first day of school for students

b. School Calendar Days

c. Saturdays

d. Summer

e. Spring break

f. On the job / job embedded training

12) Which subject areas do you teach?

13) What grade levels do you teach?

14) What is the highest degree you have earned?

15) How many years have you been teaching?

\section{Appendix B}

\section{Educational Consultancy Interview Questions}

These interview questions are designed for Educational Consultancy firms in Lebanon. The questions will address the perceptions of EC firms regarding professional development of teachers' needs.

RQ 2: How do educational consultants prepare for PD sessions/programs? 
1) How do you plan for PD sessions? What are the factors that you take into consideration when you plan for PD sessions?

2) How are PD sessions being selected? Who participates in selecting and designing PD sessions and programs?

3) How often would you rate teachers' experience and expectations of the PD sessions that you offered?

4) What are the most frequent PD offerings/courses you provide or organize?

5) Have you ever found or faced any discrepancy between teachers' perceptions of PD and what you offer to them for PD? Show me some evidence.

6) What are the strategies and tools that are used in the delivery of PD sessions?

7) How do you schedule the time?

8) How is information being gathered about teachers' needs for PD? Explain how this information is being utilized to identify the goals and priorities of PD?

9) How do you monitor and follow up on the implementation of what teachers learn from professional development activities?

10) What are the qualifications that you have? For how long you've been conducting PD programs?

\section{Appendix C}

\section{Teachers' Familiarity in PD topics}

\begin{tabular}{|c|c|c|c|c|c|}
\hline Question 8 & Not familiar & $\begin{array}{l}\text { limited } \\
\text { familiarity }\end{array}$ & $\begin{array}{l}\text { moderate } \\
\text { familiarity }\end{array}$ & high familiarity & Total \\
\hline 21st Century Skills & 0 & 10 & 50 & 40 & 100 \\
\hline Classroom Management & 0 & 10 & 50 & 40 & 100 \\
\hline Collaborative Teaching & 0 & 5 & 55 & 40 & 100 \\
\hline $\begin{array}{l}\text { Curriculum Mapping / Reading across the } \\
\text { curriculum }\end{array}$ & 0 & 15 & 60 & 25 & 100 \\
\hline Differentiated Instruction & 5 & 30 & 60 & 5 & 100 \\
\hline Grading Rubrics/Formative Assessment & 10 & 30 & 30 & 30 & 100 \\
\hline Leadership Development & 0 & 25 & 45 & 30 & 100 \\
\hline School Culture/Ethics & 0 & 0 & 50 & 50 & 100 \\
\hline Technology Integration & 0 & 5 & 55 & 40 & 100 \\
\hline Self-awareness and improvement & 0 & 0 & 60 & 40 & 100 \\
\hline organizational behavior & 0 & 5 & 55 & 40 & 100 \\
\hline Overcoming obstacles in education & 0 & 10 & 85 & 5 & 100 \\
\hline character education and development & 0 & 5 & 80 & 15 & 100 \\
\hline
\end{tabular}

\section{Appendix D}

\section{Teachers' Interest in PD topics}

\begin{tabular}{|c|c|c|c|c|c|}
\hline Question 8 & No interest & Little interest & Moderate Interest & Strong interest & Total \\
\hline 21st Century Skills & 5 & 5 & 15 & 75 & 100 \\
\hline Classroom Management & 0 & 5 & 20 & 75 & 100 \\
\hline Collaborative Teaching & 0 & 20 & 10 & 70 & 100 \\
\hline Curriculum Mapping / Reading across the curriculum & 0 & 5 & 15 & 80 & 100 \\
\hline Differentiated Instruction & 0 & 5 & 35 & 60 & 100 \\
\hline Grading Rubrics/ Formative Assessment & 0 & 10 & 35 & 55 & 100 \\
\hline Leadership Development & 0 & 5 & 15 & 75 & 100 \\
\hline School Culture/Ethics & 0 & 10 & 30 & 60 & 100 \\
\hline Technology Integration & 0 & 10 & 35 & 55 & 100 \\
\hline Self-awareness and improvement & 0 & 5 & 10 & 85 & 100 \\
\hline Overcoming obstacles in education & 0 & 0 & 50 & 50 & 100 \\
\hline organizational behavior & 0 & 10 & 30 & 60 & 100 \\
\hline character education and development & 5 & 0 & 15 & 80 & 100 \\
\hline
\end{tabular}




\section{Copyrights}

Copyright for this article is retained by the author, with first publication rights granted to the journal.

This is an open-access article distributed under the terms and conditions of the Creative Commons Attribution license (http://creativecommons.org/licenses/by/4.0/). 